\title{
DISCRETE-TIME SLIDING-MODE WMR CONTROL BASED ON PARAMETER IDENTIFICATION
}

\author{
A. FILIPESCU ${ }^{1 *}$, U. NUNES $^{2}$, S. STAMATESCU ${ }^{3}$
}

\author{
${ }^{1}$ University "Dunarea de Jos" of Galati, Department of Automation and Industrial \\ Informatics, Domneasca,no.47, 800008,Galati,Romania, Adrian.Filipescu@ugal.ro \\ ${ }^{2}$ Institute of Systems and Robotics, University of Coimbra-Polo II, \\ 3030-290, Coimbra,Portugal, Urbano@isr.uc.pt \\ ${ }^{3}$ ASTI Control S.A, Calea Plevnei, 139, Bucharest, Romania, Sabin@asticontrol.ro
}

\begin{abstract}
In this paper a discrete-time adaptive sliding mode controller for wheeled mobile robots (WMR) is presented. The dynamical model with time-varying mass has been taken into account. The sliding-mode controller has designed on two components, corresponding to angular and position motion, respectively. In order to accomplish the robustness against parameter uncertainties (robot mass and moment of inertia), an on-line closed loop identification scheme is proposed. In both, angular and position motion controllers, on-line estimation of parameters, which depend on robot mass, is used. Copyright $($ C 2005 IFAC
\end{abstract}

Keywords: discrete-time, robust adaptive sliding mode controller, wheeled mobile robot

\section{INTRODUCTION ${ }^{1}$}

Different approaches have been proposed in the literature for stabilization of wheeled mobile robots (WMR) (Canudas de Wit and Sordalen, 1997, Canudas de Wit, Siciliano and Valavanis, 1998). The control problem of non-holonomic systems when there are model uncertainties has been widely addressed. Relatively few results have been presented about the robustness of WMR control concerning model uncertainties and external disturbances. The performing control design, using the kinematical model of the vehicle does not explicitly take into account parameters variation (robot mass and moment of inertia) and external disturbances (frictions and viscous forces). Therefore, in certain situations the kinematics model of the WMR can be restrictive for controller design. The kinematical model is a simplified representation and does not correspond to reality of moving vehicle, which has unknown or time-varying mass and frictions. All of these have well pointed out in Fierro and Lewis, 1997. Therefore, the dynamical model seems to be more relevant concerning uncertainties The controller design using the WMR dynamical model, where

\footnotetext{
${ }^{1}$ This work was partially supported by Portuguese FCT and POSI, projects TSM02 and NCT04.
}

uncertainties in the robot physical parameters can be explicitly taken into account, tends to interest actual researches on this field (Coelho and Nunes, 2002). The structural (parameter) and/or un-structural uncertainties in the model of the MIMO non-linear systems and the difficulties in parameter identification, make necessary the design of the controller such that the closed loop robustness is achieved. It is well known that the robustness to structural, un-structural uncertainties and external disturbances of the WMR closed loop can be achieved with a variable structure controller (Aghilar et al. 1997; Filipescu at al. 2003; Yu and Xu 2002). Maintaining the system on a sliding surface weakens the influence of the uncertainties in the closed loop and quickly leads to an equilibrium point. The main advantage of the discrete-time sliding mode control is with the direct and easy real-time implementation. Since the sliding mode control is original from continuous time, it is more difficult to choose a synthesis in discrete-time. The discrete-time sliding mode control (Young et al. 1999; Yu and Xu, 2002) is quite different of performing the control design in the continuous-time domain. Many implementations are based on discretization, with sufficiently fast sampling rate, of the controllers designed in continuous-time. Discrete-time sliding mode controller design is usually based on an approximate 
sliding-mode system evolution due to the non unique attractiveness condition and approximate evolution on sliding surface (Furuta 1990; Yu and Xu, 2002). The robust trajectory tracking problem has been addressed in Yang and Kim, 1999 using a continuous time sliding mode control technique.

In this paper, the trajectory tracking problem for unicycle-type WMR, in the presence of uncertainties (time varying mass), has been solved by discrete-time sliding mode control law based on the discrete-time WMR dynamical model. The asymptotic boundedness of the tracking error has been proofed.

The paper is organized as follows. In Section 3 the dynamical model of a unicycle-type WMR is presented. State apace model, its uncertainties and non-holonomic constraint are presented, too. The discrete-time state-space dynamic model and the output tracking errors of the WMR are given in Section 3. Section 4 describes an on-line parameter identification scheme. The sliding mode adaptive controller, associated to angular and position motion, are designed in Section 5 and Section 6. Closed loop simulation results are presented in Section 7.

\section{CONTINUOUS-TIME WMR DYNAMICAL MODEL}

Figure 1 shows the schema of a WMR, where $\mathrm{X}^{\prime} \mathrm{Y}^{\prime}$ is a mobile frame attached to the unicycle and $\mathrm{XY}$ defines an inertial reference system. The vehicle dynamics is fully described by a three dimensional vector of generalized coordinates $\mathrm{q}(\mathrm{t})$ constituted by the coordinates $((\mathrm{x}(\mathrm{t}), \mathrm{y}(\mathrm{t})))$ of the midpoint between the two driving wheels, and by the orientation angle $\Phi(\mathrm{t})$ The velocity constraint (non-holonomic constraint) of vehicle motion is $\dot{\mathrm{x}} \sin \Phi-\dot{\mathrm{y}} \cos \Phi=0$.

Assumption 1. The WMR motion is supposed to be pure rolling, without of any slipping.

Define by $\tau_{\mathrm{r}}$ and $\tau_{1}$ the torques provided by DC motors to the right and left wheel, respectively. The vehicle is described by the following dynamical model (Fierro and Lewis, 1997)

$$
\begin{aligned}
& m \ddot{x}=-m \dot{y} \dot{\Phi}+\frac{\tau_{r}+\tau_{1}}{r} \cos \Phi \\
& m \ddot{y}=m \dot{x} \dot{\Phi}+\frac{\tau_{r}+\tau_{1}}{r} \sin \Phi \\
& I \ddot{\Phi}=\frac{D}{2 r}\left(\tau_{r}-\tau_{1}\right)
\end{aligned}
$$

where $\mathrm{m}, \mathrm{I}, \mathrm{D}, \mathrm{r}$ are the robot mass, moment of inertia, distance between wheels and wheels radius, respectively. The real mass of the WMR is supposed to be time-varying with bounded uncertainty with known nominal mass. Due to the time-varying mass, the moment of inertia becomes time-depending with bounded uncertainty.

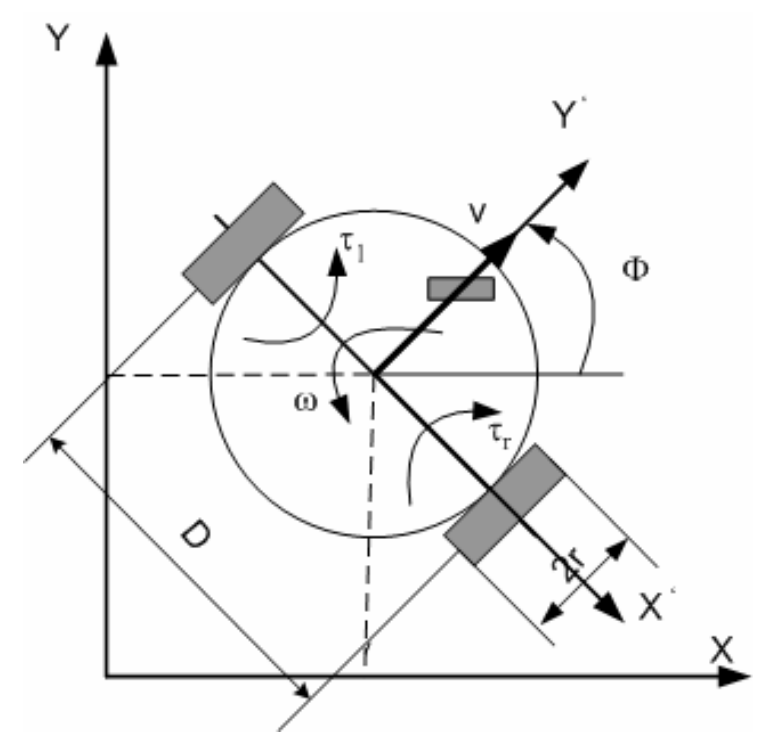

Fig.1. Definition of configuration variables.

Assumption 2. Even if the moment of inertia is considered time-varying, the robotic mass is supposed to be uniformly distributed all the time.

Let define two parameters corresponding to the angular and position motion, such as: $\alpha(\mathrm{t})=\frac{\mathrm{D}}{2 \mathrm{I}(\mathrm{t}) \mathrm{r}}$, $\pi(t)=\frac{1}{m(t) r}$. The real values of the parameters are time-varying with upper bounded uncertainties

$$
\begin{array}{ll}
\alpha^{\text {real }}(\mathrm{t})=\alpha^{\text {nom }}-\Delta \alpha(\mathrm{t}) ; & |\Delta \alpha| \leq \Delta \alpha^{\max } \\
\pi^{\text {real }}(\mathrm{t})=\pi^{\text {nom }}-\Delta \pi(\mathrm{t}) ; & |\Delta \pi| \leq \Delta \pi^{\max }
\end{array}
$$

Let $\mathrm{x} \in \mathrm{R}^{6}$ be the state vector, whose elements are

$$
\begin{aligned}
& \mathrm{x}_{1}=\mathrm{x}, \quad \mathrm{x}_{2}=\mathrm{y}, \quad \mathrm{x}_{3}=\Phi \\
& \mathrm{x}_{4}=\dot{\mathrm{x}}, \quad \mathrm{x}_{5}=\dot{\mathrm{y}}, \quad \mathrm{x}_{6}=\dot{\Phi}
\end{aligned}
$$

Define the control input corresponding to angular and position motion, respectively: $\mathrm{u}_{\mathrm{A}}=\tau_{\mathrm{r}}-\tau_{1}$, $\mathrm{u}_{\mathrm{P}}=\tau_{\mathrm{r}}+\tau_{1}$

\section{DISCRETE-TIME WMR DYNAMICAL MODEL}

The state space representation of WMR and the nonholonomic constraint will be discretized with the sampling period $\mathrm{T}$, replacing the derivative by a finite difference and using a zero-order-hold for the control inputs

$$
\begin{aligned}
& \mathrm{x}_{1}(\mathrm{k}+1)=\mathrm{x}_{1}(\mathrm{k})+\mathrm{Tx}_{4}(\mathrm{k}) \\
& \mathrm{x}_{2}(\mathrm{k}+1)=\mathrm{x}_{2}(\mathrm{k})+\mathrm{Tx}_{5}(\mathrm{k}) \\
& \mathrm{x}_{3}(\mathrm{k}+1)=\mathrm{x}_{3}(\mathrm{k})+\mathrm{Tx}_{6}(\mathrm{k}) \\
& \mathrm{x}_{4}(\mathrm{k}+1)=\mathrm{x}_{4}(\mathrm{k})-\mathrm{Tx}_{5}(\mathrm{k}) \mathrm{x}_{6}(\mathrm{k})+\mathrm{T} \pi(\mathrm{k}) \cos \left(\mathrm{x}_{3}(\mathrm{k})\right) \mathrm{u}_{\mathrm{P}}(\mathrm{k}) \\
& \mathrm{x}_{5}(\mathrm{k}+1)=\mathrm{x}_{5}(\mathrm{k})+\mathrm{Tx}_{4}(\mathrm{k}) \mathrm{x}_{6}(\mathrm{k})+\mathrm{T} \pi(\mathrm{k}) \sin \left(\mathrm{x}_{3}(\mathrm{k})\right) \mathrm{u}_{\mathrm{P}}(\mathrm{k}) \\
& \mathrm{x}_{6}(\mathrm{k}+1)=\mathrm{x}_{6}(\mathrm{k})+\mathrm{T} \alpha(\mathrm{k}) \mathrm{u}_{\mathrm{A}}(\mathrm{k})
\end{aligned}
$$


$\mathrm{x}_{4}(\mathrm{k}) \sin \left(\mathrm{x}_{3}(\mathrm{k})\right)-\mathrm{x}_{5}(\mathrm{k}) \cos \left(\mathrm{x}_{3}(\mathrm{k})\right)=0$

$\mathrm{k}$ being the $\mathrm{k}^{\text {th }}$ time interval where the corresponding variable is evaluated $(t=k T)$. Let $e(k) \in R^{6}$ be, the vector of output errors: $e_{i}(k)=x_{i}(k)-x_{i}^{\text {ref }}(k)$, where $\mathrm{x}_{\mathrm{i}}^{\mathrm{ref}}(\mathrm{k}) ; \mathrm{i}=1, \cdots, 6$ is the trajectory to be tracked.

\section{ON-LINE PARAMETER ESTIMATOR}

Due to the time-varying of the WMR mass, the control input parameters $\alpha(\mathrm{t})$ and $\pi(\mathrm{t})$ are on-line updated in order to be used in the corresponding sliding mode control input. The robustness against mass uncertainty will be assured. The maximum bounds of control input parameters corresponding to angular and linear motion will be used in the attractiveness condition of appropriate sliding surface. As will be shown in the next sections, the attractiveness condition of the corresponding sliding surface only on certain interval is satisfied. Outside of it, on-line parameter estimates will be used to compute the control input. Moreover, in discretetime, the sliding condition with some approximation is satisfied. When the system is inside of the sliding sector or in the neighborhood of sliding surface, the parameter updating law can provide convergent estimates. Let $\mathrm{S}_{\mathrm{A}}(\mathrm{k})$ and $\mathrm{S}_{\mathrm{P}}(\mathrm{k})$ be two sliding surfaces corresponding to the control input for angular and position motion, respectively. As parameter updating law, the recursive least squares method is used.

The control input for angular motion has two terms: the first one, denoted compensation part $\mathrm{u}_{\mathrm{A}}^{\text {comp }}(\mathrm{k})$ has to compensate the rotational dynamics; the second one, denoted sliding mode part $\mathrm{u}_{\mathrm{A}}^{\mathrm{sm}}(\mathrm{k})$, corresponds to system evolution inside of sliding surface neighborhood. The whole control input for angular motion is

$\mathrm{u}_{\mathrm{A}}(\mathrm{k})=\mathrm{u}_{\mathrm{A}}^{\mathrm{comp}}(\mathrm{k})+\mathrm{u}_{\mathrm{A}}^{\mathrm{sm}}(\mathrm{k})$

The calculus and the steps for getting both components of the angular motion control input are given in Section 5. Expressing the estimated value for angular motion control input parameter, $\hat{\alpha}(\mathrm{k})=\alpha^{\text {nom }}-\Delta \hat{\alpha}(\mathrm{k}), \quad$ the next sequence, corresponding to recursive least squares method (Ljung, 1999; Stoica and Ahgren, 2002) can be used to provide an estimation of the uncertainty scalar term $\Delta \alpha(\mathrm{k})$ at the $\mathrm{k}^{\text {th }}$ step

$$
\begin{aligned}
& \mathrm{L}_{\Delta \alpha}(\mathrm{k})=\frac{\mathrm{P}_{\Delta \alpha}(\mathrm{k}-1) \mathrm{u}_{\mathrm{A}}(\mathrm{k}-1)}{1+\left[\mathrm{u}_{\mathrm{A}}(\mathrm{k}-1)\right]^{2} \mathrm{P}_{\Delta \alpha}(\mathrm{k}-1)} \\
& \mathrm{P}_{\Delta \alpha}(\mathrm{k})=\mathrm{P}_{\Delta \alpha}(\mathrm{k}-1)-\mathrm{L}_{\Delta \alpha}(\mathrm{k}) \mathrm{u}_{\mathrm{A}}(\mathrm{k}-1) \mathrm{P}_{\Delta \alpha}(\mathrm{k}-1)
\end{aligned}
$$

$$
\Delta \hat{\alpha}(\mathrm{k})=\Delta \hat{\alpha}(\mathrm{k}-1)+\mathrm{L}_{\Delta \alpha}\left[\begin{array}{l}
\Delta \hat{\alpha}(\mathrm{k}-1) \mathrm{u}_{\mathrm{A}}(\mathrm{k}-1) \\
+\alpha^{\mathrm{nom}} \mathrm{u}_{\mathrm{A}}(\mathrm{k}-1) \\
-\frac{\mathrm{S}_{\mathrm{A}}(\mathrm{k})}{\mathrm{T}^{2}}
\end{array}\right]
$$

Since just one parameter is estimated, the gain $\mathrm{L}_{\Delta \alpha}(\mathrm{k})$ and the covariance $\mathrm{P}_{\Delta \alpha}(\mathrm{k})$ are scalars.

Concerning the position motion control input parameter, $\hat{\pi}(\mathrm{k})=\pi^{\text {nom }}-\Delta \hat{\pi}(\mathrm{k})$, the same updating law is used

$$
\begin{aligned}
& \mathrm{L}_{\Delta \pi}(\mathrm{k})=\frac{\mathrm{P}_{\Delta \pi}(\mathrm{k}-1) \mathrm{u}_{\mathrm{P}}(\mathrm{k}-1)}{1+\left[\mathrm{u}_{\mathrm{P}}(\mathrm{k}-1)\right]^{2} \mathrm{P}_{\Delta \pi}(\mathrm{k}-1)} \\
& \mathrm{P}_{\Delta \pi}(\mathrm{k})=\mathrm{P}_{\Delta \pi}(\mathrm{k}-1)-\mathrm{L}_{\Delta \pi}(\mathrm{k}) \mathrm{u}_{\pi}(\mathrm{k}-1) \mathrm{P}_{\Delta \pi}(\mathrm{k}-1) \\
& \Delta \hat{\pi}(\mathrm{k})=\Delta \hat{\pi}(\mathrm{k}-1)+\mathrm{L}_{\Delta \pi}(\mathrm{k})\left[\begin{array}{l}
\mathrm{T} \Delta \hat{\pi}(\mathrm{k}-1) \mathrm{u}_{\mathrm{P}}(\mathrm{k}-1) \\
+\pi^{\text {nom }} \mathrm{u}_{\mathrm{P}}(\mathrm{k}-1) \\
+\widetilde{\mathrm{S}}_{\mathrm{P}}(\mathrm{k})-\mathrm{S}_{\mathrm{P}}(\mathrm{k})
\end{array}\right]
\end{aligned}
$$

where $\mathrm{L}_{\Delta \pi}(\mathrm{k}), \mathrm{P}_{\Delta \pi}(\mathrm{k})$ have the same meaning as previously and $\widetilde{\mathrm{S}}_{\mathrm{P}}(\mathrm{k})$ will be defined later .

Remark 1. For both parameter updating laws, (9) and (12), the expression in brackets is valid when the system evolutes in the neighborhood of the corresponding sliding surface.

\section{CONTROL INPUT FOR ANGULAR MOTION}

In order to design the control input for angular motion, the following sliding surface has been chosen

$\mathrm{S}_{\mathrm{A}}(\mathrm{k})=\mathrm{A}(\mathrm{k}+1)-\mu \mathrm{A}(\mathrm{k})=0$

$\mathrm{A}(\mathrm{k})=\mathrm{x}_{3}(\mathrm{k})-\operatorname{arctg}\left(\frac{\mathrm{x}_{5}^{\mathrm{ref}}(\mathrm{k})-\delta_{2} \mathrm{e}_{2}(\mathrm{k}-1)}{\mathrm{x}_{4}^{\mathrm{ref}}(\mathrm{k})-\delta_{1} \mathrm{e}_{1}(\mathrm{k}-1)}\right)$

where $\mu \in\left(\begin{array}{ll}-1 & 1\end{array}\right), \delta_{1}, \delta_{2} \in\left(\begin{array}{ll}0 & \frac{1}{\mathrm{~T}}\end{array}\right)$. The dynamics of sliding surface is given by $\mu$ and by the position errors: $\mathrm{e}_{1}, \mathrm{e}_{2}$. The interval set of $\delta_{1}$ and $\delta_{2}$ assures the stability of position errors. If the nonholonomic constraint corresponding to the reference trajectory

$$
\mathrm{x}_{3}^{\mathrm{ref}}(\mathrm{k})=\arctan \left(\frac{\mathrm{x}_{5}^{\mathrm{ref}}(\mathrm{k})}{\mathrm{x}_{4}^{\mathrm{ref}}(\mathrm{k})}\right)
$$

is taken into account, then the angular error $\mathrm{e}_{3}(\mathrm{k})$ vanish when $\mathrm{e}_{1}(\mathrm{k}), \mathrm{e}_{2}(\mathrm{k})$ tend to zero.

Remark 2. The sliding surface defined in (13) has been chosen such as whenever a sliding mode is achieved on it and $\mathrm{e}_{1}(\mathrm{k}), \mathrm{e}_{2}(\mathrm{k})$ vanish, the orientation angle $\Phi$ tends to its reference value. 
For computing the control input, the following attractiveness condition (Furuta, 1990; Yu and Xu, 2002) has been used:

$\mathrm{S}_{\mathrm{A}}(\mathrm{k}) \Delta \mathrm{S}_{\mathrm{A}}(\mathrm{k}+1)<-\frac{1}{2} \Delta \mathrm{S}_{\mathrm{A}}^{2}(\mathrm{k}+1)$

$\Delta \mathrm{S}_{\mathrm{A}}(\mathrm{k}+1)=\mathrm{S}_{\mathrm{A}}(\mathrm{k}+1)-\mathrm{S}_{\mathrm{A}}(\mathrm{k})$

It assures an approximate sliding mode on the surface (13). If for the compensation part of the control input the expression

$$
\begin{aligned}
& \mathrm{u}_{\mathrm{A}}^{\mathrm{comp}}(\mathrm{k})=\left(\mathrm{T}^{2} \alpha^{\text {nom }}\right)^{-1} \\
& {\left[\begin{array}{l}
\operatorname{arctg}\left(\frac{\mathrm{x}_{5}^{\mathrm{ref}}(\mathrm{k}+2)-\delta_{2} \mathrm{e}_{2}(\mathrm{k}+1)}{\mathrm{x}_{4}^{\mathrm{ref}}(\mathrm{k}+2)-\delta_{1} \mathrm{e}_{1}(\mathrm{k}+1)}\right) \\
+\mathrm{x}_{3}(\mathrm{k}+1)-\mathrm{Tx}_{6}(\mathrm{k})-\mu \mathrm{A}(\mathrm{k}+1)
\end{array}\right]}
\end{aligned}
$$

is chosen, then, after replacing (6), (13) and (14) in (17) one obtains

$$
\begin{aligned}
& \Delta \mathrm{S}_{\mathrm{A}}(\mathrm{k}+1)=\mathrm{T}^{2}\left(\alpha^{\text {nom }}-\Delta \alpha(\mathrm{k})\right) \mathrm{u}_{\mathrm{A}}^{\mathrm{sm}}(\mathrm{k}) \\
& +\Delta \alpha(\mathrm{k}) \mathrm{u}_{\mathrm{A}}^{\mathrm{comp}}(\mathrm{k})-\mathrm{S}_{\mathrm{A}}(\mathrm{k})
\end{aligned}
$$

With (19), (16) becomes

$$
\begin{aligned}
& \mathrm{T}^{2}\left[\alpha^{\text {nom }}-\Delta \alpha(\mathrm{k})\right]^{2}\left[\mathrm{u}_{\mathrm{A}}^{\mathrm{sm}}(\mathrm{k})\right]^{2} \\
& +2 \mathrm{~T}^{2}\left[\alpha^{\text {nom }}-\Delta \alpha(\mathrm{k})\right] \Delta \alpha(\mathrm{k})\left|\mathrm{u}_{\mathrm{A}}^{\mathrm{sm}}(\mathrm{k})\right|\left|\mathrm{u}_{\mathrm{A}}^{\mathrm{comp}}(\mathrm{k})\right| \\
& +\mathrm{T}^{2}[\Delta \alpha(\mathrm{k})]^{2}\left[\mathrm{u}_{\mathrm{A}}^{\operatorname{comp}}(\mathrm{k})\right]^{2}-\left[\mathrm{S}_{\mathrm{A}}^{2}(\mathrm{k})\right]^{2}<0
\end{aligned}
$$

Introducing the upper bound of the angular motion parameter uncertainty, the above second degree inequality can be written in the compact form

$\mathrm{T}^{2}\left[\begin{array}{l}\left.\left(\alpha^{\text {nom }}-\Delta \alpha^{\max }\right) \mathrm{u}_{\mathrm{A}}^{\mathrm{sm}}(\mathrm{k}) \mid\right]^{2} \\ +\Delta \alpha^{\max }\left|\mathrm{u}_{\mathrm{A}}^{\mathrm{comp}}(\mathrm{k})\right|\end{array}\right]^{2}-\left[\mathrm{S}_{\mathrm{A}}^{2}(\mathrm{k})\right]^{2}<0$

If $\mathrm{u}_{\mathrm{A}}^{\mathrm{sm}}(\mathrm{k})>0$ and $\frac{\left|\mathrm{S}_{\mathrm{A}}(\mathrm{k})\right|}{\mathrm{T}^{2}}>\Delta \alpha \max \left|\mathrm{u}_{\mathrm{A}}^{\text {comp }}(\mathrm{k})\right|$, then the sliding-mode part of the control input can be expressed as

$$
\mathrm{u}_{\mathrm{A}}^{\mathrm{sm}}(\mathrm{k})<\frac{\left|\frac{\mathrm{S}_{\mathrm{A}}(\mathrm{k})}{\mathrm{T}^{2}}\right|-\Delta \alpha^{\max }\left|\mathrm{u}_{\mathrm{A}}^{\text {comp }}(\mathrm{k})\right|}{\alpha^{\text {nom }}-\Delta \alpha^{\max }}
$$

When $\mathrm{u}_{\mathrm{A}}^{\mathrm{sm}}(\mathrm{k})<0$, the inequality (21) is satisfied for

$$
\mathrm{u}_{\mathrm{A}}^{\mathrm{sm}}(\mathrm{k})>-\frac{\left|\frac{\mathrm{S}_{\mathrm{A}}(\mathrm{k})}{\mathrm{T}^{2}}\right|-\Delta \alpha^{\max }\left|\mathrm{u}_{\mathrm{A}}^{\text {comp }}(\mathrm{k})\right|}{\alpha^{\text {nom }}-\Delta \alpha^{\max }}
$$

Remark 3. Both expressions of the sliding-mode part, (22) and (23), can be written compactly
$\mathrm{u}_{\mathrm{A}}^{\mathrm{sm}}(\mathrm{k})=\rho_{\mathrm{A}} \frac{\left|\frac{\mathrm{S}_{\mathrm{A}}(\mathrm{k})}{\mathrm{T}^{2}}\right|-\Delta \alpha^{\max }\left|\mathrm{u}_{\mathrm{A}}^{\text {comp }}(\mathrm{k})\right|}{\alpha^{\text {nom }}-\Delta \alpha^{\max }}$

where $\rho_{\mathrm{A}} \in\left(\begin{array}{ll}-1 & 1\end{array}\right)$.

When $\frac{\left|\mathrm{S}_{\mathrm{A}}(\mathrm{k})\right|}{\mathrm{T}^{2}} \leq \Delta \alpha^{\max }\left|\mathrm{u}_{\mathrm{A}}^{\text {comp }}(\mathrm{k})\right|$, the attractiveness condition (16) can not be satisfied. The sliding mode part of the control input still can be computed by using estimates of parameter $\Delta \alpha$. The recursive least square method used to compute $\Delta \hat{\alpha}$, given by (7), (8) and (9), is convergent only when the system evolves in the neighborhood of sliding surface. Therefore, an approximate sliding mode condition is satisfied $\frac{\mathrm{S}_{\mathrm{A}}(\mathrm{k}+1)}{\mathrm{T}^{2}} \approx 0$

$\left[\alpha^{\text {nom }}-\Delta \hat{\alpha}(\mathrm{k})\right] \mathrm{u}_{\mathrm{A}}^{\mathrm{sm}}(\mathrm{k})+\Delta \hat{\alpha}(\mathrm{k}) \mathrm{u}_{\mathrm{A}}^{\mathrm{comp}}(\mathrm{k}) \approx 0$

This approximate is used in order to compute the control input for angular motion

$\mathrm{u}_{\mathrm{A}}^{\mathrm{sm}}(\mathrm{k})=-\frac{\Delta \hat{\alpha}(\mathrm{k}) \mathrm{u}_{\mathrm{A}}^{\mathrm{comp}}(\mathrm{k})}{\alpha^{\text {nom }}-\Delta \hat{\alpha}(\mathrm{k})}$

Remark 4. Using (24), the updating law (9) can be rewritten as

$\Delta \hat{\alpha}(\mathrm{k})=\Delta \hat{\alpha}(\mathrm{k}-1)$
$+\mathrm{L}_{\Delta \alpha}\left[\begin{array}{l}{\left[\alpha^{\mathrm{nom}}-\Delta \hat{\alpha}(\mathrm{k}-1)\right] \mathrm{u}_{\mathrm{A}}^{\mathrm{sm}}(\mathrm{k}-1)} \\ +\Delta \hat{\alpha}(\mathrm{k}-1) \mathrm{u}_{\mathrm{A}}^{\mathrm{comp}}(\mathrm{k}-1)-\frac{\mathrm{S}_{\mathrm{A}}(\mathrm{k})}{\mathrm{T}^{2}}\end{array}\right]$

\section{CONTROL INPUT FOR POSITION MOTION}

The following sliding surface is proposed

$$
\begin{aligned}
& \mathrm{S}_{\mathrm{P}}(\mathrm{k})=\sqrt{\left[\mathrm{x}_{4}(\mathrm{k})\right]^{2}+\left[\mathrm{x}_{5}(\mathrm{k})\right]^{2}} \\
& -\sqrt{\left[\mathrm{x}_{4}^{\mathrm{ref}}(\mathrm{k})-\delta_{1} \mathrm{e}_{1}(\mathrm{k}-1)\right]^{2}+\left[\mathrm{x}_{5}^{\mathrm{ref}}(\mathrm{k})-\delta_{2} \mathrm{e}_{1}(\mathrm{k}-1)\right]^{2}} \\
& =0
\end{aligned}
$$

Starting with the third equation of model (4), using a trigonometric equality and the non-holonomic constraint (5), the following equality holds

$$
\operatorname{tg}\left(\operatorname{Tx}_{6}(\mathrm{k})\right)=\frac{\frac{\mathrm{x}_{5}(\mathrm{k}+1)}{\mathrm{x}_{4}(\mathrm{k}+1)}-\frac{\mathrm{x}_{5}(\mathrm{k})}{\mathrm{x}_{4}(\mathrm{k})}}{1+\frac{\mathrm{x}_{5}(\mathrm{k}+1) \mathrm{x}_{5}(\mathrm{k})}{\mathrm{x}_{4}(\mathrm{k}+1) \mathrm{x}_{4}(\mathrm{k})}}
$$

Moreover, introducing the expressions of the state variables, from state model (4), and using the constraint (5), the above equality becomes

$$
\begin{aligned}
& \operatorname{tg}\left(\operatorname{Tx}_{6}(\mathrm{k})\right)\left(\sqrt{\left[\mathrm{x}_{4}(\mathrm{k})\right]^{2}+\left[\mathrm{x}_{5}(\mathrm{k})\right]^{2}}-\mathrm{T} \pi(\mathrm{k}) \mathrm{u}_{\mathrm{P}}(\mathrm{k})\right) \\
& =\operatorname{Tx}_{6}(\mathrm{k}) \sqrt{\left[\mathrm{x}_{4}(\mathrm{k})\right]^{2}+\left[\mathrm{x}_{5}(\mathrm{k})\right]^{2}}
\end{aligned}
$$


Define

$$
\begin{aligned}
& \widetilde{\mathrm{S}}_{\mathrm{P}}(\mathrm{k})=\left[\left|\cos \left(\mathrm{Tx}_{6}(\mathrm{k})\right)\right|\right]^{-1} \sqrt{\left[\mathrm{x}_{4}(\mathrm{k})\right]^{2}+\left[\mathrm{x}_{5}(\mathrm{k})\right]^{2}} \\
& -\sqrt{\left[\mathrm{x}_{4}^{\mathrm{ref}}(\mathrm{k}+1)-\delta_{1} \mathrm{e}_{1}(\mathrm{k})\right]^{2}+\left[\mathrm{x}_{5}^{\mathrm{ref}}(\mathrm{k}+1)-\delta_{2} \mathrm{e}_{2}(\mathrm{k})\right]^{2}}
\end{aligned}
$$

The sliding motion on the surface (27) concerns the reduced order system of the robotic model, without of $3^{\text {rd }}$ and $6^{\text {th }}$ equation. The same attractiveness condition (Furuta, 1990)

$$
\begin{aligned}
& \mathrm{S}_{\mathrm{P}}(\mathrm{k}) \Delta \mathrm{S}_{\mathrm{P}}(\mathrm{k}+1)<-\frac{1}{2} \Delta \mathrm{S}_{\mathrm{P}}^{2}(\mathrm{k}+1) \\
& \Delta \mathrm{S}_{\mathrm{P}}(\mathrm{k}+1)=\mathrm{S}_{\mathrm{P}}(\mathrm{k}+1)-\mathrm{S}_{\mathrm{P}}(\mathrm{k})
\end{aligned}
$$

for computing the position motion control input has been considered. It assures an approximate sliding mode on the surface (27). Consequently of slidingmode evolution on (13), the angular state $\mathrm{x}_{3}(\mathrm{k})$ tends to hold the following expressions

$$
\begin{aligned}
& \cos \left(\operatorname{Tx}_{3}(\mathrm{k})\right) \\
& =\frac{\mathrm{x}_{4}^{\mathrm{ref}}(\mathrm{k})-\delta_{1} \mathrm{e}_{1}(\mathrm{k}-1)}{\sqrt{\left[\mathrm{x}_{4}^{\mathrm{ref}}(\mathrm{k})-\delta_{1} \mathrm{e}_{1}(\mathrm{k}-1)\right]^{2}+\left[\mathrm{x}_{5}^{\mathrm{ref}}(\mathrm{k})-\delta_{2} \mathrm{e}_{1}(\mathrm{k}-1)\right]^{2}}} \\
& =\frac{\mathrm{x}_{5}^{\mathrm{ref}}(\mathrm{k})-\delta_{1} \mathrm{e}_{1}(\mathrm{k}-1)}{\sqrt{\left[\mathrm{Tx}_{3}(\mathrm{k})\right)}}
\end{aligned}
$$

Using (28), the following expression can be obtained

$$
\begin{aligned}
& {\left[\mathrm{x}_{4}(\mathrm{k}+1)\right]^{2}+\left[\mathrm{x}_{5}(\mathrm{k}+1)\right]^{2}} \\
& =\frac{\left[\sqrt{\left[\mathrm{x}_{4}(\mathrm{k})\right]^{2}+\left[\mathrm{x}_{5}(\mathrm{k})\right]^{2}}-\mathrm{T}\left(\pi^{\mathrm{nom}}-\Delta \pi(\mathrm{k})\right) \mathrm{u}_{\mathrm{P}}(\mathrm{k})\right]^{2}}{\left[\cos \left(\mathrm{Tx}_{6}(\mathrm{k})\right)\right]^{2}}
\end{aligned}
$$

With (35) and (29), (25) and (32) become

$$
\begin{aligned}
& \mathrm{S}_{\mathrm{P}}(\mathrm{k}+1)=\widetilde{\mathrm{S}}_{\mathrm{P}}(\mathrm{k}) \\
& -\mathrm{T}\left|\cos \left(\mathrm{Tx}_{6}(\mathrm{k})\right)\right|^{-1}\left(\pi^{\mathrm{nom}}-\Delta \pi(\mathrm{k})\right) \mathrm{u}_{\mathrm{P}}(\mathrm{k}) \\
& \Delta \mathrm{S}_{\mathrm{P}}(\mathrm{k}+1)=\widetilde{\mathrm{S}}_{\mathrm{P}}(\mathrm{k})-\mathrm{S}_{\mathrm{P}}(\mathrm{k}) \\
& =\mathrm{T} \mid \cos \left(\mathrm{Tx}_{6}(\mathrm{k})\right)^{-1}\left(\pi^{\text {nom }}-\Delta \pi(\mathrm{k})\right) \mathrm{u}_{\mathrm{P}}(\mathrm{k})
\end{aligned}
$$

Using (36), (37) and upper bound of position motion uncertainty, from (2), the second degree inequality can be written

$\left[\frac{\left(\pi^{\text {nom }}-\Delta \pi^{\max }\right) T}{\left|\cos \left(\mathrm{Tx}_{6}(\mathrm{k})\right)\right|}\left|\mathrm{u}_{\mathrm{P}}(\mathrm{k})\right|+\left|\widetilde{\mathrm{S}}_{\mathrm{P}}(\mathrm{k})\right|\right]^{2}-\left[\mathrm{S}_{\mathrm{P}}(\mathrm{k})\right]^{2}<0$

If $\mathrm{u}_{\mathrm{P}}^{\mathrm{sm}}(\mathrm{k})>0$ and $\left|\mathrm{S}_{\mathrm{P}}(\mathrm{k})\right|>\left|\widetilde{\mathrm{S}}_{\mathrm{P}}(\mathrm{k})\right|$, then the sliding control input for position motion can be expressed as

$$
\mathrm{u}_{\mathrm{P}}(\mathrm{k})=\rho_{\mathrm{P}} \frac{\mathrm{S}_{\mathrm{P}}(\mathrm{k})-\left|\widetilde{\mathrm{S}}_{\mathrm{P}}(\mathrm{k})\right|}{\mathrm{T}\left[\left|\cos \left(\mathrm{Tx}_{6}(\mathrm{k})\right)\right|\right]^{-1}\left(\pi^{\mathrm{nom}}-\Delta \pi^{\mathrm{max}}\right)}
$$

where $\rho_{P} \in\left(\begin{array}{ll}0 & 1\end{array}\right)$. When $\left|\mathrm{S}_{\mathrm{P}}(\mathrm{k})\right| \leq\left|\widetilde{\mathrm{S}}_{\mathrm{P}}(\mathrm{k})\right|$, the attractiveness condition (31) can not be satisfied. The control input still can be computed using on-line estimates for $\Delta \pi$

Remark 5. The recursive least square method used to compute $\Delta \hat{\pi}$, given by (10), (11) and (12), is convergent only when the system evolves in the neighborhood of sliding surface. Therefore, the approximate sliding mode condition is satisfied, $\mathrm{S}_{\mathrm{P}}(\mathrm{k}+1) \approx 0$

$\mathrm{T}\left[\mid \cos \left(\operatorname{Tx}_{6}(\mathrm{k})\right)\right]^{-1}\left(\pi^{\text {nom }}-\Delta \hat{\pi}(\mathrm{k})\right) \mathrm{u}_{\mathrm{P}}(\mathrm{k})+\widetilde{\mathrm{S}}_{\mathrm{P}}(\mathrm{k}) \approx 0$

From above, the control input can be expressed as

$\mathrm{u}_{\mathrm{P}}(\mathrm{k})=-\frac{\widetilde{\mathrm{S}}_{\mathrm{P}}(\mathrm{k})}{\mathrm{T}\left[\mathrm{cos}\left(\mathrm{Tx}_{6}(\mathrm{k})\right)\right]^{-1}\left(\pi^{\mathrm{nom}}-\Delta \hat{\pi}(\mathrm{k})\right)}$

Remark 6. As result of (40), (12) can be rewritten as

$$
\begin{aligned}
& \Delta \hat{\pi}(\mathrm{k})=\Delta \hat{\pi}(\mathrm{k}-1) \\
& +\mathrm{L}_{\Delta \pi}(\mathrm{k})\left[\begin{array}{l}
\mathrm{T}\left[\cos \left(\mathrm{Tx}_{6}(\mathrm{k}-1)\right)\right]^{-1}\left[\pi^{\mathrm{nom}}-\Delta \hat{\pi}(\mathrm{k}-1)\right] \\
\mathrm{u}_{\mathrm{P}}(\mathrm{k}-1)+\widetilde{\mathrm{S}}_{\mathrm{P}}(\mathrm{k}-1)-\mathrm{S}_{\mathrm{P}}(\mathrm{k})
\end{array}\right]
\end{aligned}
$$

When the system evolves in sliding-mode on the surface (27), $\quad \mathrm{x}_{4}(\mathrm{k})=\mathrm{x}_{4}^{\mathrm{ref}}(\mathrm{k})-\delta_{1} \mathrm{e}_{1}(\mathrm{k}-1) \quad$ and $\mathrm{x}_{5}(\mathrm{k})=\mathrm{x}_{5}^{\text {ref }}(\mathrm{k})-\delta_{2} \mathrm{e}_{1}(\mathrm{k}-1)$. Therefore, output tracking error dynamics associated to the reduced order system can be expressed as

$$
\begin{aligned}
& \mathrm{e}_{1}(\mathrm{k}+1)=\mathrm{e}_{1}(\mathrm{k})-\delta_{1} \mathrm{Te}_{1}(\mathrm{k}-1) \\
& \mathrm{e}_{2}(\mathrm{k}+1)=\mathrm{e}_{2}(\mathrm{k})-\delta_{2} \mathrm{Te}_{2}(\mathrm{k}-1)
\end{aligned}
$$

For $\delta_{1}, \delta_{2} \in\left(0 \frac{1}{\mathrm{~T}}\right)$, the above dynamics errors are stable.

\section{CLOSED LOOP SIMULATION RESULTS}

For testing the proposed discrete-time sliding-mode adaptive controller, Scout WMR has been chosen. In simulations, the following parameters of model (3) were used: $\mathrm{m}=80 \mathrm{~kg}, \quad \mathrm{D}=0.34 \mathrm{~m}, \quad \mathrm{r}=0.1 \mathrm{~m}$, $\mathrm{I}=2,312 \mathrm{kgm}^{2}, \mathrm{~T}=0.3 \mathrm{~s}$. The moment of inertia has been computed assuming the mass uniformly distributed. A linear-time varying mass additionally to the nominal one has been considered. More precisely, the robotic time-varying mass has been increased linearly from $80 \mathrm{~kg}$ to $110 \mathrm{~kg}$. The closed loop structure, shown in the figure 2 , has been tested by simulation. The simulation results, shown in figures 3 and 4 , were obtained for $\Delta \alpha^{\max }=0.4$, $\Delta \pi^{\max }=0.033$, The following values have been chosen for the constants: $\mu=0.001$, $\rho_{\mathrm{P}}=\rho_{\mathrm{A}}=0.99$, $\delta_{1}=\delta_{2}=3.33$, $\mathrm{P}_{\Delta \alpha}(0)=\mathrm{P}_{\Delta \pi}(0)=10$. 


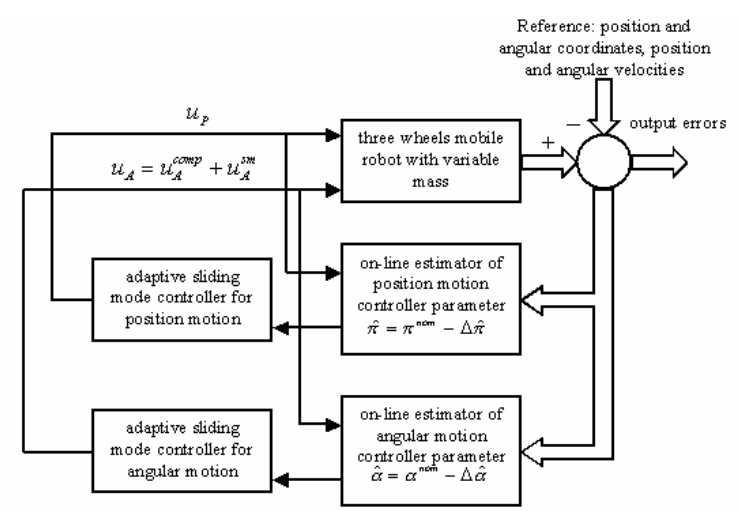

Fig. 2. Closed loop block schema of sliding modeadaptive WMR control
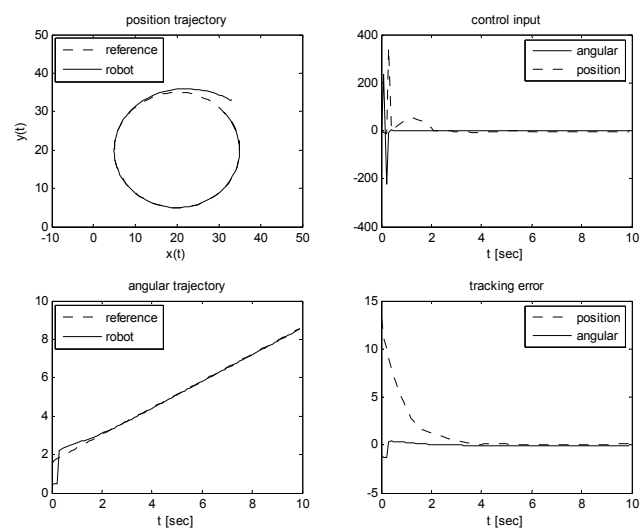

Fig. 3. WMR closed loop response for circular reference and initial conditions $\mathrm{x} 1(0)=33$; $\mathrm{x} 2(0)=33 ; \mathrm{x} 3(0)=\pi / 7 ; \mathrm{x} 4(0)=-0.5 ; \times 5(0)=0.2$; $\mathrm{x} 6(0)=0.1$
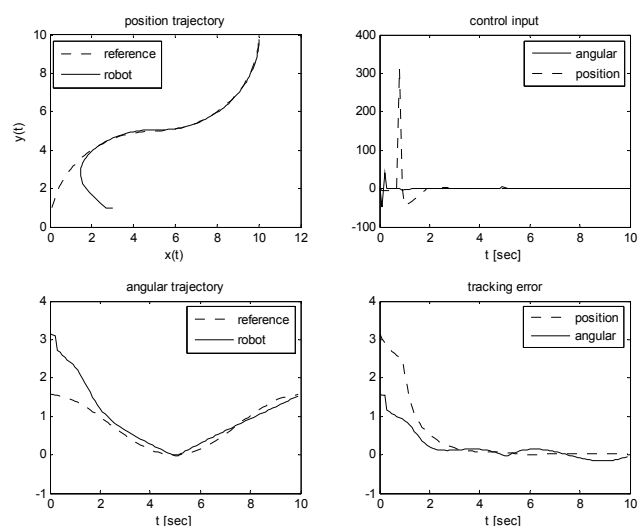

Fig. 4. WMR closed loop response for "sinusoidal" reference and initial conditions $\mathrm{x}(0)=3$; $\mathrm{x} 2(0)=1 ; \mathrm{x} 3(0)=\pi ; \mathrm{x} 4(0)=-0.5 ; \mathrm{x} 5(0)=-0.1$; $\mathrm{x} 6(0)=-0.2$

\section{CONCLUSIONS}

A discrete-time sliding mode adaptive controller for trajectory tracking of unicycle-type WMRs has presented in this paper. The time-varying mass dynamical state space model has been undertaken in order to design the controller. Even if as parameter uncertainty, only the robotic mass has been considered, the proposed controller assures closed loop robustness to a wide typology of parameter and model uncertainties and external disturbances. Two components of the sliding mode adaptive controller have been designed, for angular and position motion, respectively. The robustness is guaranteed by sliding mode controller and by an adaptive parameter identification scheme. Controller parameters, on-line updated, assure an approximate sliding mode evolution even if the attractiveness condition is not satisfied and, moreover contribute to an increased robustness. Closed-loop simulation results using the parameter values of a Nomad Scout WMR were presented which show the effectiveness of the proposed trajectory tracking controller.

\section{REFERENCES}

Aghilar, L. E., Hamel, T. and Soueres, P. (1997). Robust path-following control for wheeled robots via sliding mode techniques. Proc. of the IEEE/RSJ International Conference on Intelligent Robots and Systems, vol. 3, pp 13891395 .

Canudas de Wit, C. and Sordalen, O. J. (1992). Exponential stabilisation of mobile robots with nonholonomic constraints. IEEE Transactions on Automatic Control, 37, pp 1791-1797.

Canudas de Wit, C., Siciliano, B., and Valavanis, K.P. (1998). Trends in mobile robot and vehicle control, in Control Problems in Robotica, Lecture Notes in Control and Information Science, Springer- Verlag, 1998, vol.230, pp.151-176.

Coelho, P., and Nunes, U (2004), Path following control of robotic wheelchair, $5^{\text {th }}$ IFAC Symposium on Intelligent and Autonomous Vehicles, June, Lisbon, Portugal.

Fierro, R. and Lewis, F.L. (1997), Robust practical point stabilization of a nonholonomic mobile robot using neural networks, Journal of Intelligent and Robotic Systems, 20. 295-317.

Filipescu, A., Dugard, L. and Dion J. M. (2003). Smooth variable structure observer-controller with adaptive gain. Application to robot manipulators control. European Control Conference, ECC03, Sep., Cambridge, U.K.

Furuta, K., (1990), Sliding mode control of a discrete system. System \& Control Letters, vol. 14, pp.145-152.

Leo, T and Orlando, G. (1998). Discrete-time sliding mode control of a nonholonomic mobile robot. Proc. of the Nonlinear Control Systems design Symposium, NOLCOS1998 (pp.575-580).

Ljung, L., (1999) System Identification ( $2^{\text {nd }}$ edition). Prentice-Hall, NJ.

Stoica, P. and Ahgren P., (2002) Exact initialisation of the recursive least squares algorithm. International Journal of Adaptive Control and Signal Processing, vol. 16, pp. 219-230.

Yang J.,M. and Kim, J. H. (1999) Sliding mode control for trajectory tracking of nonholonomic wheeld mobile robots, IEEE Transactions on Robotics and Automation, 15(3), pp.578-587.

Young, K.D., Utkin, V.I., and Ozguner, U., (1999). A control engineer's guide to sliding mode control. IEEE Transactions on Control Systems Technology, 7(3), pp.328-342.

$\mathrm{Yu}, \mathrm{X} ., \mathrm{Xu}, \mathrm{J} ., \mathrm{X} ., \quad$ (2002) Variable Structures Systems: Towards $21^{\text {st }}$ Century, SpringerVerlag, Berlin Heidelberg. 